Noticias y Comentarios

\title{
Indicadores para la evaluación del estado de conservación de ciudades históricas ${ }^{1}$
}

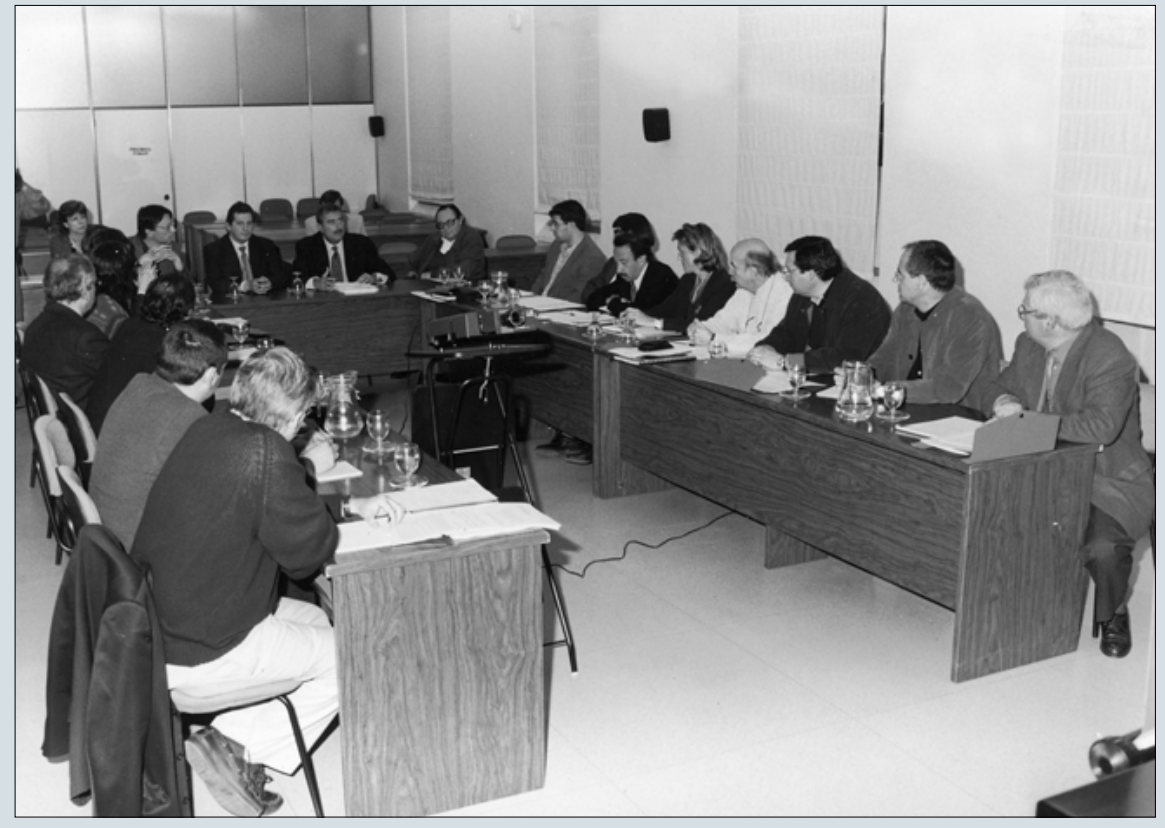

Sesión de trabajo durante el encuentro de expertos en Úbeda y Baeza

El Proyecto Indicadores para la Evaluación del Estado de Conservación de Ciudades Históricas se atiene a un marco general de referencia que es el Patrimonio entendido como sistema, con una visión integrada donde deben incorporarse las actividades correspondientes al conocimiento, régimen jurídico, conservación, disfrute y rentabilidad social de los recursos y en un contexto que atienda al desarrollo cultural y a una mejor calidad de vida.

El progreso de este proyecto servirá de apoyo a los organismos públicos para mantener la tutela integral de las Ciudades Históricas y adoptar medidas que eviten el deterioro y a veces desaparición definitiva de sus valores culturales y sociales. Al mismo tiempo facilitará a los ciudadanos la práctica de un derecho fundamental como es la participación activa en la conservación y acrecentamiento del Patrimonio Cultural.

El Proyecto Indicadores es expresión de una filosofía donde el indicador en sí mismo representa el final de un proceso de análisis y comprensión del hecho cultural que puede generar en el futuro amplias expectativas para el Patrimonio, conociendo mejor sus recursos y su capacidad de progreso.
Los indicadores facilitarán en un futuro el establecimiento de fundamentos o principios que garanticen una protección adecuada de las ciudades históricas inscritas en el Patrimonio Mundial, sentando las bases de una política de protección internacional que haga posible crear y consolidar un patrimonio común de la Humanidad.

Los Indicadores confeccionados en Colonia de Sacramento, tienen un grado de generalidad saludable pero su aplicación requiere una precisión mayor y la revisión de determinados parámetros que contemplen la totalidad del proceso de formación de los mismos, a través de los documentos elaborados en el curso de las dos reuniones de Colonia de Sacramento y Úbeda - Baeza y las aportaciones que se realicen a lo largo de los próximos encuentros.

El principio de diversidad de los indicadores para adaptarse a los diferentes casos que se planteen, con objeto de atender a las cualidades intrínsecas del lugar, debe compatibilizarse con un objetivo general que consiste en encontrar aquellos sistemas de medida que sean universales y tengan una clara y fácil aplicación.
El Patrimonio Cultural incluye valores específicos complejos de medir y a los que no resulta fácil aplicar sistemas de control que son habituales en otros campos de las ciencias sociales. La aceptación de esta complejidad no debe excluir el intento de racionalización que el Proyecto Indicadores lleva implícito. Por lo que una de las conclusiones más importantes de esta reunión de Úbeda - Baeza consiste en aceptar una contingencia: la necesidad de estudios más precisos en los que participen las disciplinas necesarias relacionadas con la sociología, la economía, etc.

Los indicadores requieren no sólo una redefinición y concreción mayores sino también una aplicación a casos específicos que permita comprobar su idoneidad, cuestión que no es necesario plantear desde cero sino aprovechar las experiencias que se conocen en el planeamiento urbano, en los proyectos de promoción cultural, en la difusión de acciones sobre el Patrimonio Cultural, etc. Por esta razón se propone una aplicación estratégica a Ciudades Históricas que sean representativas de diversas escalas y problemáticas.

El Proyecto Indicadores requiere pasar en definitiva a una fase de investigación que desarrolle las etapas que se han cubierto y por otra parte determinar qué tipo de aplicación se pretende en un futuro próximo y el grado de compromiso de los organismos públicos que apoyan el Proyecto. De esta forma se podrán conocer con mayor exactitud la velocidad y exigencias del proceso a seguir.

En la reunión celebrada en Úbeda - Baeza se han destacado una serie de cuestiones que se van a enumerar, en algunos aspectos coincidentes o redundantes con las propuestas de Colonia de Sacramento, pero que conviene resaltar en cualquier caso porque obedecen a una nueva reflexión que incide en las políticas sobre el Patrimonio Cultural.

\section{Los indicadores y las políticas patrimoniales y urbanísticas}

- Las Ciudades Históricas deben expresar sus objetivos, sus proyectos, sistemas de control, participación, previsiones económicas, relación con otras ciudades y territorios etc. 
a través de un Plan de Gestión que incluya Planes Directores, Planes de Desarrollo Urbano etc., por lo que debe medirse no sólo la existencia de los mismos sino también su fiabilidad y su aplicación en el tiempo.

- Las áreas históricas tienen una relación de gran interés con sus entornos y forman parte de entidades de mayor rango que deben interesarnos especialmente para una adecuada conservación y equilibrio, por lo que reclamamos una atención constante a la ciudad a la que pertenecen y a su territorio.

- Es necesario evaluar la incidencia en las Ciudades Históricas de patrimonios de diversa índole: bienes muebles e inmuebles, arqueología, patrimonio inmaterial etc. cuyo censo a través de catálogos o instrumentos afines debe recomendarse como pauta de registro, difusión y tutela de sus valores.

- Los impactos causados por la acción de diversos agentes son determinantes en muchas circunstancias, afectando directamente a las Ciudades Históricas y a su territorio, por lo que destacamos la necesidad de preverlos, analizarlos y medirlos de forma adecuada.

- Una de las cualidades más relevantes de las Ciudades Históricas lo constituye la multiplicidad de usos que está presente en su estructura, con una trama residencial especialmente relevante de la que es preciso conocer su situación, las condiciones de renovación, sustitución, adaptación a las necesidades de los habitantes etc. Además de la atención que debe prestar el Proyecto Indicadores a esta realidad, se recomienda que los poderes públicos emprendan acciones ejemplares para la recuperación de los tejidos residenciales en nuestras ciudades.

- Es fundamental mantener el equilibrio entre espacio libre y suelo edificado en nuestras ciudades, por lo que debe verificarse su evolución en el tiempo y alertar sobre aquellos cambios que lo desvirtúen.

- Debe concederse una especial atención a la adecuación de la arquitectura contemporánea a la escala, valores y usos del patrimonio existente en las Ciudades Históricas.

- El turismo y el consumo de los bienes culturales son actividades determinantes de este final de siglo que suponen el desplazamiento de personas, bienes y servicios con una especial incidencia en las Ciudades
Históricas y sus economías. Creemos necesario garantizar un equilibrio adecuado con los recursos culturales, la población y las actividades de dichas ciudades por lo que es necesario detectar y corregir las situaciones de sobreexplotación o desvirtuación de sus condiciones de vida.

- La accesibilidad, relacionada con el transporte colectivo, el tráfico y las infraestructuras viarias y de aparcamiento, condiciona la habitabilidad de las Ciudades Históricas por lo que los indicadores deberán atender especialmente a su evolución.

- Los programas de formación, intercambio y cooperación para un mejor conocimiento de las técnicas de conservación, estudio, intervención, gestión, etc. sobre el Patrimonio Cultural, son indicativos de la solidez de los procesos que atienden a la especial problemática de las Ciudades Históricas. Por esta razón la existencia, grado de desarrollo e implicación de estos programas en la comunidad urbana es un índice muy importante de la atención que se presta a su patrimonio.

\section{Los indicadores en relación con las políticas culturales}

- Es necesario conocer las políticas que promueven un desarrollo humano y sostenible y que contribuyan al florecimiento de las diferentes culturas, ya que se entiende como un signo de vitalidad que una comunidad sitúe la política cultural como un componente esencial de sus estrategias.

- La promoción de la creatividad y la diversidad, la participación de los ciudadanos en la vida cultural y en definitiva el acceso al Patrimonio Cultural, son aspectos que se pueden medir a través del Proyecto Indicadores como un referente esencial en la evolución de las Ciudades Históricas.

\section{Los indicadores sociales}

- Es necesario definir el perfil que deben tener los estudios de población en las Ciudades Históricas para conocer sus características y la evolución de los parámetros más importantes que nos hablen de densidad, composición, permanencia, emigración etc.

- La vitalidad de las comunidades urbanas se refleja fundamentalmente a través de los procesos de acción y participación, por lo que debe destacarse como una condición esencial su consideración en los procesos de medición y verificación de la evolución de las Ciudades Históricas. El mantenimiento de tradiciones, fiestas, etc. que pertenecen al patrimonio inmaterial, resultan afectadas con excesiva frecuencia por las transformaciones que tienen lugar en nuestras ciudades por lo que resulta fundamental el conocimiento sobre su preservación y evolución.

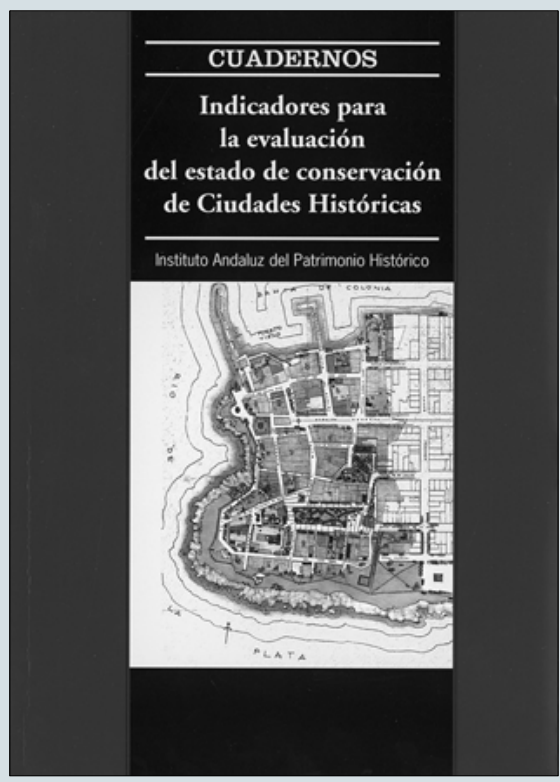

Publicación editada por el IAPH con motivo de la reunión de Indicadores

\section{Los indicadores económicos}

- Deben estudiarse cuestiones que atienden a los factores económicos de las Ciudades Históricas: renta, inversiones, reversión en la comunidad, empleo etc.

- Los recursos económicos que se destinan al Patrimonio Cultural resultan fundamentales para el conocimiento de los procesos de transformación de las Ciudades Históricas, por lo que debe atenderse a su cuantificación, aplicación e idoneidad.

Pedro Salmerón Escobar Arquitecto

I. Ponencia marco de la Reunión de estudios e investigación sobre Centros Históricos Patrimonio de la Humanidad, celebrada en las ciudades de Úbeda y Baeza (Jaén), en abril de 1999. Más información sobre el proyecto en el editorial del n 26 (abril 1999) de PH. Boletín del IAPH y en la publicación Indicadores para la evaluación del estado de conservación de Ciudades Históricas. 